\title{
The Nature of Organizational Culture in Indian Knowledge Organizations
}

\author{
Effulgence \\ Vol. 16 No. 2 \\ July - December, 2018 \\ Rukmini Devi Institute of Advanced Studies \\ E-mail : effulgence@rdias.ac.in, Website : www.rdias.ac.in \\ http:/ / effulgence.rdias.ac.in/user/default.aspx \\ https://dx.doi.org/10.33601/effulgence.rdias/v16/i2/2018/42-56
}

\section{Dr. Mohnish Kumar ${ }^{1}$}

\begin{abstract}
The main purpose of this paper is to figure out the nature of the Organizational Culture in the six selected Knowledge Organizations and how they vary across the public and private sector organizations as well as on the sectoral lines viz., Power Sector Vs. IT sector Vs. other infrastructure sector organizations and in the perception of different genders from a random sample of 204 Knowledge Workers. The data about the Organizational Culture and background variables including demographic variables have been collected using a questionnaire-survey technique through the questionnaire given by Pareek (1997). The Principal Component Analysis was used to figure out the nature of organizational culture and the multiple regression analysis with dummy variable was used to differentiate among sectors and genders. The Principal Component Analysis throws up only one Principal Component out of eight variables, which suggests the unitary nature of the Organizational Culture. The unitary nature of Organizational Culture prevalent in the selected Knowledge Organization supports the Integration Perspective of the Organizational culture. The integration perspective helps in the Knowledge Management and can safely argued that it is nothing but "Knowledge-Centered Culture" in the selected Knowledge Organizations. There is no significant difference in the positive ethos or Organizational culture of the Public Sector and Private Sector Knowledge Organizations, and of the IT Sector and Infrastructure Sector Knowledge Organizations including Power Sector Organizations. However, the female Knowledge Workers perceive more Positive ethos than the male Knowledge Workers in their respective organizations.
\end{abstract}

Keywords: Organizational Culture, OCTAPACE, Positive Ethos, Knowledge-Centered Culture, Knowledge Organization.

\section{INTRODUCTION}

$\mathrm{E}$ very organization has unique organizational culture that not only provides special identity to an organization like personality of an Individual but also influences the behavior of employees by directing them to think, feel, and act as expected in the organization (Kumar, 2012). The word 'culture' has different meaning in different context and used differently by different people. For a lay person, it indicates sophistication, e.g., someone is very "cultured". The anthropologists use it to refer to the customs and rituals that societies develop over the course of their history. In modern times in the

\section{Assistant Professor, Dr. Bhim Rao Ambedkar College, University of Delhi, mohnishkumar@gmail.com}


organizational context, it is used to indicate the climate and practices or espoused values and credo of the organization (Schein, 1992, p-3). Organizational culture suggests the collective perceptions, beliefs, and values of employees in the workplace and Individuals come to know about it on the very first day in the office (Debowski, 2006, p83). Culture can also be defined as the accumulated shared learning of a given group and these shared learning as values get ingrained into pattern called culture (Schein, 1992, p-10).

Schein (1992) pointed out that the Cultural analysis illuminates subcultural dynamics within organizations, e.g., communication failures or lack of teamwork, or integration of several organizational sub-groups; Cultural analysis is necessary if we are to understand how new technologies influence and are influenced by organizations, e.g., use of IT and its impact on transforming work or misadventure of implementing IT unless cultural perspective are taken into consideration. The management tries to do Cultural analysis, as this paper propose to do, for several issues at hand e.g., cultural problems in several mergers and acquisitions; cultural resistance in the Organizational learning, development, and planned change (pp. xii-xiv).

Schein $(1983,1992)$ specified that the primary task of leaders of organization to develop and actively reinforce strong organizational cultures. Organizational culture positively impacts retention of employees (Sheridan, 2002), Knowledge Creation (Kumar, 2013, 2014), Knowledge Capture (Kumar, 2016) and productivity (Kopelman et al., 1990). Newell et al., (2002) argued that the strong organizational cultures are those values and ethos which are widely shared across the organization ( $\mathrm{p}$ 33).

Schein (1992) argued for better study and proper understanding of the dynamics of culture in an organization to take into account the resistance to change and irrational behavior of the employees.

\section{REVIEW OF LITERATURE}

A large body of literature has been produced by researchers and academicians of anthropology and sociology and others relating to the area of culture in the 1940s and 1950s. However, Organizational culture studies started around early 1970s (Clark, 1972), which was later incorporated into management literature during 1980s (Deal and Kennedy, 1982). Schein's (1981, 1983, 1984, 1985) work has revolutionized it further. However, Schein's approach based on the unitary perspective of the organizational culture was critiqued and challenged (Barley, 1983).

\section{PERSPECTIVES ON ORGANIZATIONAL CULTURE}

There are mainly three perspectives on organizational culture developed by Martin and Meyerson (1988) as follows and their differences are explained in Table 1 in the appendix:

\section{Integration perspective on culture:}

According to Martin and Meyerson (1988), the Integration Perspective of culture represents culture in terms of organization-wide consistency, consensus, and clarity. From an integration perspective, there is no room for ambiguity (Frost et al., 1991). The integration perspective on culture assumes that certain structural preconditions such as a well-defined hierarchy and highly centralized decision making and this is an overriding assumption in Schein's work and all of the business excellence literature that it is in fact feasible for leaders of firms to actively create and shape an organizational culture which promotes integration and consensus around dominant organizational values (Newell et al., 2002).

\section{Differentiation perspective on culture:}

Several studies with the differential perspective represent predominantly inconsistent cultural 
manifestations. According to these studies, the extent to which the consensus and clarity emerge, it does so only within the boundaries of a subculture. At the organizational level, different subcultures may co-exist and ambiguity is channeled outside the sub-cultural boundaries (Frost et al., 1991).

\section{Fragmentation perspective on culture:}

The fragmentation perspective views ambiguity as most prevalent aspect of Organizational Culture. These studies focus predominantly on the experience and expression of ambiguity within organizational cultures. Clear consistencies, like clear inconsistencies, are rare. According to this viewpoint, consensus and dissensus co-exist in a constantly fluctuating pattern influenced by changes, e.g., in events, attention, salience, and cognitive overload. Any cultural manifestation can be, and is, interpreted in a myriad of ways. No clear organization-wide or sub-cultural consensus stabilizes when a culture is viewed from a fragmentation point of view (Frost et al., 1991).

The fragmentation perspective suggests that culture is better viewed as a metaphor rather than a variable- something an organization is rather than something an organization has. From this perspective, culture is only loosely structured and partially shared, emerging dynamically as organizational members experience each other, events and the organizational context over time (Martin, 1992). The fragmentation perspective importantly legitimates differentiation- that is, competing and contradictory value systems held by individuals across the firm. This perspective acknowledges ambiguity, recognizing that within organizations individuals might experience a lack of clarity or simultaneously hold multiple meanings and beliefs. Lack of clarity can result from unclear structures, organizational boundaries or precise goals (Newell et al., 2002, p-35).

The term "Organizational Culture" connotes different things to different scholars. Most of the time, very little difference or no difference was found among the words values, ethics, beliefs, ethos, climate and culture and these words are used interchangeably. Pareek (1997) proposed the idea of Ethos as the underlying spirit or character of an entity or group and is made up of its beliefs, customs, or practices and core values at the base of it. The eight important values relevant to institution building are as follows, whose acronym came out to be OCTAPACE (Pareek, 1997).

Openness: Pareek (1997) defined openness as, one of the ethos, a spontaneous expression of feelings and thought, and sharing of these without defensiveness, that too in both directions such as orders and suggestions as well as feedback and criticism. Openness means receiving without reservation and giving without hesitation. Openness allows open environment where an employee can submit without retribution as well as free and frequent interactions with other colleagues in the organization. Greater openness in the organizations is reflected in productive meetings and effective implementation of plans (Pareek, 1997).

Confrontation: As defined by Pareek (1997), confrontation ethos is more prevalent when most of the employees try to approach a problem with the intension to solve it rather than leave the problem or pass the buck in the organization. Pareek (1997) argued that this ethos is better represented by the term 'confrontation and exploration' (CE). It results in more clarity regarding roles, more conversation and discussion and resolving conflicts and solving a problem

Trust: Trust refers to sense of assurance that commitments and obligations will be honored as well as others will help when needed and will not misuse the information already shared (Pareek, 1997). Kumar (2017a) highlighted the role of trust in the institution building and other aspects of organizational life. Higher trust ethos helps in institution building, timely support, stress reduction, reduction in procedures and paperwork, and greater 
production (Pareek, 1997).

Authenticity: Authenticity is defined by Pareek (1997) in terms of absence of difference in what someone in the organization feels, says, and does. It is the correspondence between reality and perception in the organization. The presence of authenticity ethos in an organization leads to less distortion and confusion in the communication (Pareek, 1997).

Proaction: Pareek (1997) defined Proaction as taking the initiative, preplanning, and taking preventive action, and calculating the payoffs before taking action. In opposite to reaction, proaction relates to preplanning and starting a new process or new procedures or new behavioral patterns. Proaction is not just new but also unique behavior. This operates at the following three levels:

Proaction at the feeling level results in greater empathy, proaction, at the thinking level, leads to preplanning and taking care of more contingencies, and at the action level, proaction leads new set of actions that alters the regular course of events. The outcome of higher proactivity will be less "emergency" meetings in organizations and with customers, willingness to enter new areas of work, timely curtailing of unprofitable business. All these can also be used as indicators of proaction, including better capital management (Pareek, 1997).

Autonomy: Autonomy has been defined by Pareek (1997) in terms of independence and freedom in the individual's sphere of influence. The higher prevalence of autonomy ethos in the organization leads to effective delegation and decentralization.

Collaboration: Pareek (1997) defined collaboration as ethos as helpful ethos prevalent in the organization and it leads to better coordination, effective team-work and efficient sharing of resources.

Experimenting: Pareek (1997) defined experimenting ethos as new and unique ways of handling things in the organization to solve a problem and taking-risk. This results in adopting new approaches and more creativity and innovation in the organization.

\section{Perspective of organizational culture relevant for knowledge Organizations:}

Even though the structural conditions of an organization is helpful in the Knowledge work, it is not difficult to get creativity and innovation subdued (Starbuck, 1992). Newell et al., (2002) argued that even particular norms and informal routines might hamper in the Knowledge and creative work because it might quickly become standardized ways of things in the organizations and embedded in the best practices as well as organizational culture. The knowledge organizations need to focus not only on the structural conditions such as flexible and autonomous team-working as a precondition but also on the cultural conditions to improve and promote knowledge work (Newell et al., 2002). Several empirical research papers proved that the organizational culture collectively influences the Knowledge Creation (Kumar, 2013), Knowledge Capture (Kumar, 2016) and Knowledge Management per se (Kumar, 2012).

There are mainly two schools of organizational culture which are relevant to knowledge organizations viz., the integration perspective and differentiation perspective. The integration perspective of organizational culture argues that there should be strong organizational culture in the organization as to integrate the whole organization as one unit. Newell et al., (2002) summarized this perspective by suggesting organizations needs to have strong organizational culture which is widely shared across the organization for better productivity in Knowledge work. The integration perspective on organizational culture (Martin, 1992) proposes that the culture is an organizational variable that can be directly shaped by the leaders of the organization. Newell et al., (2002) argued that the 
core values and beliefs of a leader spread throughout the organization and impact the values, ethos and norms of behavior of other Knowledge workers which consequently influence knowledge work.

However, asking educated and skilled knowledge workers with broader latitude of acceptance and diverse values, beliefs, and norms to forgo and forget their uniqueness, identity, values, beliefs, interests and attitudes and to assume shared values and belief of the organization would be too much for any knowledge worker (Newell et al., 2002).

From the differentiation perspective, culture is only loosely structured and partially shared, emerging dynamically as organizational members experience each other, events and the organizational context over time (Martin, 1992). Newell et al., (2002) suggested that the leaders of such organizations need to accept that leaders are only in a position to loosely manage organizational culture. Instead of transforming every knowledge workers' values and beliefs and instilling dominant core values of the organization, the leader can promote a diverse and loosely structured as well as loosely managed culture in the organization. This will not only allow knowledge workers to identify with the organization but also make them believe it as a great place to work.

\section{HYPOTHESES}

HA1-The Organizational Culture in the selected Indian Knowledge Organization follow the Integration perspective of the Organizational Culture.

HA2-The Organizational Culture in the selected Indian Knowledge Organization follow the Differentiation perspective of the Organizational Culture.

HA3-The Organizational Culture in the selected Indian Knowledge Organization follow the Fragmentation perspective of the Organizational Culture.

HA4-The Organizational Culture is different in the
Knowledge Organizations belonging to different sectors.

HA5-Different genders of Knowledge Workers perceive Organizational Culture differently.

\section{RESEARCH METHOD}

This empirical research paper is based on the nonexperimental research design having diagnostic aspect behind the study of Organizational culture of six Knowledge Organizations belonging to both Public sector and Private sector.

\section{Objective:}

1. To figure out the nature of the Organizational Culture in the Indian Knowledge Organizations.

2. To study the Public Vs. Private sector differences in the Organizational Culture prevalent in those Knowledge Organizations.

3. To study the Sectoral differences in the Organizational Culture prevalent in the Indian Knowledge Organizations belonging to Power Sector, IT Sector and other infrastructure sectors.

4. To study the gender differences in the organizational Culture in the selected Indian Knowledge Organizations

Research questions: The most basic question that this paper tries to answer is:

1. Whether Organizational Culture in the Indian Knowledge Organization is a unitary variable and form part of Integration Perspective of the Organizational Culture or follows any other perspective?

2. What is the nature of Organizational Culture and its gender and sectoral distribution (both public sector Vs. Private Sector as well as Power sector Vs. IT Sector Vs. Other Infrastructure Sector) among six Indian Knowledge Organizations?

\section{SAMPLING DESIGN:}

From the universe of Knowledge Management 
practicing companies, a random sample of 204 Knowledge Workers were selected. These Knowledge workers belong to six Knowledge Creating Companies of India, as follows: Organization A: It operates in the power sector as one of the largest power companies in India. It considers and proclaims that Knowledge Management form part of the core of the organization. Organization B: It belongs to the top 100 Knowledge Creating company. It operates as technology and manufacturing leader, serves customers worldwide with aerospace products and services; controls technologies for buildings, homes and industry; automotive products; turbochargers; and specialty materials. Organization C: It is a global consulting, technology, training, and outsourcing company. It focuses exclusively in providing IT Services and Products. It works extensively with Clients in many major industries and services. It emphasizes on acquiring an in-depth knowledge of the customer's context and needs, and designs solutions fine-tuned to these needs. Organization D: It is one of the top global steel producing multinational organization. It is a winner of Indian Most Admired Knowledge Enterprise (MAKE) award at multiple times. It has several key Knowledge Strategies like Customer Value Management (CVM), Supplier Value Management (SVM), and Knowledge Manthan. Organization E: It is India's flagship government owned, public sector, Knowledge Creating Oil Company which covers entire hydrocarbon value chain - from refining, pipeline transportation, and marketing of petroleum products to exploration \& production of crude oil \& gas, marketing of natural gas and petrochemicals. Organization F: It is one of the top 10 Knowledge Creating, technological multinational company operating in 170 countries around the world and providing solutions for a smarter planet.

\section{MEASURES}

The primary data for this empirical research paper has been randomly collected using a selfadministered questionnaire by Pareek (1997) from the above selected six Knowledge Enterprises. The questionnaire consists of the items relating to personal details and demographic variables regarding the Knowledge Workers along with 40 items of OCTAPACE variables. The Knowledge Workers were asked to assess the presence of such practices in the daily Knowledge work.

\section{DATA COLLECTION}

The primary data from a sample of 204 Knowledge workers belonging to 6 Knowledge Creating Companies from three different sectors, viz. Power, IT and Infrastructure sectors (excluding power sector), belonging to both public and private enterprises, have been collected using surveyquestionnaire technique. For further analysis and calculation of sectoral differences, two dummy variables named "dum var sec 1 " and "dum var sec 2 " were created. The variable named "dum var sec 1 " stands for the IT sector organizations and the variable "dum var sec 2" stands for infrastructure sector organizations except power as shown in the Table 2 in the appendix. The base organization operates in the power sector.

For calculation of public sector and private sector differences, a new dummy variable by the name of "Sector" has been created, which has two values of " 0 " and " 1 ". " 0 " stands for public sector organizations and " 1 " stands for private sector organizations. Out of 204 Knowledge organizations responses, $108(52.9 \%)$ are from public sector and 96 $(47.1 \%)$ from private sector organizations.

For calculation of gender differences, a dummy variable named "dum var gender" was created which has two values of " 0 " and " 1 ". " 0 " stands for male and " 1 " stands for female. Out of 204 Knowledge Workers, $83.8 \%$ of them are male and the rest $16.2 \%$ are female.

\section{DATA ANALYSIS, RESULTS AND DISCUSSION}

Under this overwhelming literature support, the 
collected data about OCTAPACE has been analyzed using Principal Component Analysis to figure out its nature and perspective it follows. The Principal Component Analysis not only helps in figuring out the nature of the items forming part of a variable (Singh \& Kumar, 2013; Kumar, 2017b); but also whether a variable has unitary nature or not (Kumar, 2018). Later, the Multiple Regression Equation with dummy variables was used to find the sectoral and gender differences out of the Principal Component thus derived.

\section{Principal Component Analysis:}

There are eight variables in the OCTAPACE. To figure out the nature of all the eight ethos of the organization, Principal Component Analysis was applied and which has resulted in only one Principal Component as shown in Table 3 in the appendix.

The written warning, in Table 3, suggests that there is only one component could be extracted. Since there is only one component, it cannot be plotted on the graph. The Table 4 shows the descriptive statistics of all the eight variables.

If we scan the correlation or R-matrix (as shown in Table 5 - OCTAPACE Correlation Matrix), almost all the variables correlate fairly well with every other. However, none of them correlate perfectly or particularly large, therefore, there is no need to consider eliminating any item or question at this stage. To check singularity in the data, the determinant of the R-matrix should be greater than the necessary value of 0.00001 . For this data the value of the determinant is equal to 0.010 , which is greater than the requisite value. Therefore, we can be confident that multi-collinearity is not a problem for these data.

The Kaiser-Meyer-Olkin (KMO) Measure of Sampling Adequacy is 0.887 shown in Table 6, which suggests that the data adequacy is great and there is no need to collect more data or inclusion or exclusion of any more variables. For these data,
Bartlett's test is highly significant $(\mathrm{p}<0.001)$, and, therefore, principal component analysis is appropriate.

The inverse of the correlation matrix $\left(\mathrm{R}^{1}\right)$ (shown in Table 7 - Inverse of Correlation Matrix) is used in various calculations including factor scores.

The Anti-image correlation and covariance matrices (as shown in Table 8) provide similar information as there is a relationship between covariance and correlation. The KMO values can be calculated for multiple and individual variables. The KMO values for individual variables are produced on the diagonal of the anti-image correlation matrix. These are above 0.5 so none of the variables need to be removed. Almost all the off-diagonal elements are small suggesting that the analysis is moving in the right direction.

The Table 9 - Communalities shows before and after extraction. Communality is the proportion of common variance within a variable. The amount of variance in each variable that can be explained by the retained factors is represented by the communalities after extraction.

The SPSS uses Kaiser's criterion of retaining factors with eigen-values greater than 1 . In the output Table 10 - Total Variance Explained, the eigen-values associated with each linear Principal Component before extraction and after extraction. Since there is only one component that could be extracted as per Kaiser's criteria, there is no rotation value of component. SPSS then extracts all factors with eigenvalues greater than 1 , which leaves us with only one Principal Component.

The eigen-values associated with this factor are displayed (and the percentage of variance explained) in the columns labeled Extraction Sums of Squared Loadings. The values in this part for the table are same as the values before extraction, except that the values for the discarded factors are ignored. Principal component -1 which could be labeled as 
"Over-all-Culture" for later analysis has the eigenvalues of 4.722 . The output Table 11 shows the component matrix.

The matrix which is given in Table 12 - Reproduced Correlations, contains the correlation coefficients between all of the questions or items based on factor model. For the good model these values will all be small. Statistically, if more than $50 \%$ of residuals are greater than 0.05 , there is a ground for concern. In our case, it satisfies our statistical condition for good model.

The first and only Principal Component has been recorded and fed as score into the original dataset. This variable has been named and labeled as "Overall-Culture" which has all OCTAPACE ethos and their respective component score as shown in Table 13 , that has been incorporated into and termed as "Over-all-Culture" to be part of further modeling. These items have the common theme of "OCTAPACE ETHOS" or positive ethos.

The principal component analysis produced only one principal component which has been labeled as "Over-all-Culture". This variable includes all the eight paces or limbs of OCTAPACE for better understanding and further analysis.

\section{Public Sector Vs. Private Sector Differentiation}

The $t$ value of "Sector" (in the Table 14) is not significant even at $10 \%$ level of significance. The positive beta, both standardized and unstandardized, and $t$ value of the Private Sector Knowledge Organizations represented by the dummy variable "Sector" suggests that the Private Sector Knowledge Organizations are little better but not statistically significant than the Public Sector Knowledge Organizations in the area of positive ethos in their respective Organizations.

\section{Power Sector Vs. IT Sector Vs. Other Infrastructure Sector Differentiation:}

The $t$ value of "dum var sec 1" and "dum var sec 2 " (in the Table 15) is not at all significant even at 10\% level of significance with the probability of $0 \%$. The Beta, both standardized and unstandardized, as well as $t$ value of the IT sector organizations represented by "dum var sec 1" and 'Other infrastructure Sector Knowledge Organizations' represented by "dum var sec 2" is positive but their magnitude is quite low. This suggests that IT sector and 'Other infrastructure sector' Knowledge Organizations are little better but not significantly different or better than Power Sector Knowledge Organization in the area of positive ethos. So, essentially, all the selected Knowledge Organizations exhibit almost similar level of positive ethos.

\section{Gender Differentiation}

The $t$ value of "dum var gender" (in Table 16), which stands for gender, is significant at $10 \%$ level of significance. The positive beta, both standardized and unstandardized, and $t$ value of the female Knowledge Workers represented by the dummy variable "dum var gender" suggest that the female Knowledge Workers are significantly better than the male Knowledge Workers in the positive ethos in their respective Organizations.

\section{Discussion and Conclusions}

The findings generated from this empirical study not only influence academia and research but also the industry and its managers who are interested in the Organizational Culture. Since, only one Principal Component has come out after the Principal Component Analysis of eight OCTAPACE variables, thus, we accept the first alternate hypothesis that the Organizational Culture in the selected Indian Knowledge Organizations follows the integration perspective of the Organizational Culture and reject the other two alternate hypotheses about the differentiation and fragmentation perspectives about the Organizational Culture. 
There is no sectoral difference (even public-private difference or IT sector and Infrastructure sector difference) in the Organizational Culture in the six selected Knowledge Organizations. We can safely reject the fourth alternate hypothesis and accept the null hypothesis that all the selected Knowledge Organizations exhibit almost similar Organizational Culture. It can safely be said that they exhibit similar characteristics as National Culture.

However, we accept the fifth alternate hypothesis that different genders of knowledge workers perceive Organizational Culture differently. Actually, the female Knowledge workers perceive more positive ethos and the Organizational Culture.

It also shows the unitary nature of the Organizational culture in the Knowledge Organizations and we can safely say that it is nothing but "Knowledge-Centered Culture" (Janz and Prasarphanich, 2003). As pointed by Janz and Prasarphanich (2003), the Knowledge-Centered Culture, which encourage Knowledge creation and dissemination, constitutes collaboration, team oriented work environment and autonomy etc. These are the part of the positive ethos of OCTAPACE of Pareek (1997).

\section{Limitation of the Study}

This empirical research paper studies the nature of the Organizational Culture in the six selected Knowledge Organizations and their variations along the sectoral (both public Vs. private sectors as well as IT, Power and Infrastructure sectors) and gender lines. The questionnaire-survey technique has its own lacuna. Since, the primary data has been collected from only six Indian Knowledge Organizations, its generalizability and ecological validity are limited to other similar contexts.

\section{REFERENCES}

1) Barley, S. R. (1983), "Semiotics and the study of occupational and organizational cultures",
Administrative Science Quarterly, 393-413.

2) Clark, B. R. (1972), "The organizational saga in higher education", Administrative science quarterly, 178-184.

3) Deal, T. E., \& Kennedy, A. A. (1982),“Corporate cultures: The rites and rituals of organizational life", Reading-Mass: Addison-Wesley, 2, 98-103.

4) Debowski, S. S. (2006), “Knowledge Management",Milton: John Wiley \& Sons, Australia.

5) Frost, P. J., Moore, L. F., Louis, M. R., Lundberg, C. C., \& Martin, J. (Eds.). (1991), "Reframing Organizational Culture",California. Sage Publications, Inc.

6) Janz, B.D. and Prasarphanich, P. (2003), “Understanding the antecedents of effective knowledge management: the importance of a knowledge-centered culture", Decision Science, Vol. 34, No. 2, pp. 351-384.

7) Kopelman, R. E., Brief, A. P., \& Guzzo, R. A. (1990),"The role of climate and culture in productivity", In B. Schneider (Ed.), Organizational Climate and Culture, San Francisco: Jossey-Bass.

8) Kumar, M. (2012),“Knowledge management: A study of selected organizations", Unpublished Doctoral Dissertation, University of Delhi, Delhi, India.

9) Kumar, M. (2013),“Effect of leadership behaviors on knowledge creation in Indian organizations", Delhi Business Review, 14(2), 57-82.

10) Kumar, M. (2014),"The Relationship of knowledge identification and creation with leadership, culture and technology", The IUP Journal of Knowledge Management, 11(2), 7-37.

11) Kumar, M. (2016),"Relative Contribution of Knowledge Technology towards Knowledge Capture", Delhi Business Review, Vol. 17, No. 2, pp. 57-73. ISSN No-0972-222X.

12) Kumar, M. (2017a), “Organizational Trust in the Indian Knowledge Organizations", Delhi Business Review, Vol. 18, No. 1, pp. 71-82. ISSN No-0972-222X.

13) Kumar, M. (2017b), “The Nature of Leadership in the Knowledge Era: A study of Indian 
Knowledge Organizations", The IIS University Journal of Commerce \& Management, Vol. 6, No. 1, pp. 89-111. ISSN No-2320-4907.

14) Kumar, M. (2018), "Nature of Knowledge Technology across Indian Organizations", Delhi Business Review, Vol. 19, No. 1. ISSN No-0972222X.

15) Martin, J. (1992), "Cultures in Organizations", New York: Oxford University Press.

16) Martin, j., \& Meyerson, D. (1988), "Organizational culture and the denial, channeling, and acknowledgement of ambiguity", In L. R. Pondy, R. J. Boland, Jr., \& H. Thomas (Eds.), Managing ambiguity and change. New York: John Wiley.

17) Meyerson, D., \& Martin, J. (1987),“Cultural change: An integration of three different views",Journal of Management Studies, 24, 623647.

18) Newell, S., Robertson, M., Scarbrough, H., \& Swan, J. (2002),"Managing Knowledge Work”, New York: PALGRAVE.

19) Pareek, U. (1997), “Training Instruments for Human Resource Development", New Delhi, India. Tata McGraw-Hill Publishing Company Limited.

20) Schein, E. H. (1981),“Does Japanese management style have a message for American managers?", Sloan Management Review, 23(1), 55.

21) Schein, E. H. (1983), "The role of the founder in creating organizational culture", Organizational Dynamics, Summer; 13-28.

22) Schein, E. H. (1984), “Coming to a new awareness of organizational culture", Sloan management review, 25(2), 3-16.

23) Schein, E. H. (1985), “Organizational Culture and Leadership”, San Francisco, CA: Jossey-Bass.

24) Schein, E. H., (1992), “Organizational Culture and Leadership", California. USA. Jossey-Bass Inc.

25) Sheridan, J. E. (2002), “Organizational culture and employee retention", Academy of Management Journal, vol. 35.:1036-56.

26) Singh, A.K., and Kumar, M. (2013), "Organizational Leadership in India", In C.S.
Sharma and R.K. Singh (Eds.), Transformational Leadership and Beyond, New Delhi: Excel India Publishers, India, pp.53-67.

27) Starbuck, W. (1992), “Learning by knowledgeintensive firms", Journal of Management Studies, 29(6): 713-40. 
APPENDIX

Table 1 : Perspectives of Organizational Culture

\begin{tabular}{|l|l|l|l|}
\hline & \multicolumn{3}{|c|}{ Perspectives } \\
\hline Features & Integration & Differentiation & Fragmentation \\
\hline $\begin{array}{l}\text { Orientation to } \\
\text { consensus }\end{array}$ & $\begin{array}{l}\text { Organization-wide } \\
\text { consensus }\end{array}$ & Subcultural consensus & Lack of consensus \\
\hline $\begin{array}{l}\text { Relation among } \\
\text { Manifestations }\end{array}$ & Consistency & Inconsistency & $\begin{array}{l}\text { Not clearly consistent } \\
\text { or inconsistent }\end{array}$ \\
\hline $\begin{array}{l}\text { Orientation to } \\
\text { Ambiguity }\end{array}$ & Exclude it & $\begin{array}{l}\text { Channel it outside } \\
\text { subcultures }\end{array}$ & Acknowledge it \\
\hline
\end{tabular}

Source: adapted from Table 1 in Martin and Meyerson (1988) and Figure 3 in Meyerson and martin (1987) cited in Frost et al., ed. 1991, p-8.

Table 2 : Dummy variables for Sector-wise distribution of organizations

\begin{tabular}{|l|c|c|l|l|}
\hline & $\begin{array}{l}\text { dum var sec } \\
\text { 1- IT Sector }\end{array}$ & $\begin{array}{l}\text { dum var sec 2- } \\
\text { Infra. Sector } \\
\text { except power }\end{array}$ & Nosponses & Sectors \\
\hline Organization- A & 0 & 0 & 100 & Base- Power / Public Sector \\
\hline Organization- B & 1 & 0 & 38 & IT Sector / Private Sector \\
\hline Organization- C & 1 & 0 & 30 & IT Sector / Private Sector \\
\hline Organization- D & 0 & 1 & 25 & Infrastructure Sector/ Private \\
\hline Organization- E & 0 & 1 & 8 & Infrastructure Sector/ Public \\
\hline Organization- F & 1 & 0 & 3 & IT Sector / Private Sector \\
\hline TOTAL & 71 & 33 & 204 & \\
\hline
\end{tabular}

Table 3 : Warnings about single principal components

Only one component was extracted. Component plots cannot be produced. 
Table 4 : Descriptive Statistics of OCTAPACE Variables

\begin{tabular}{|l|c|c|c|c|}
\hline & Mean & Std. Deviation & Analysis N & Missing N \\
\hline Openness & 13.87 & 2.370 & 204 & 0 \\
\hline Confrontation & 14.01 & 2.502 & 204 & 0 \\
\hline Trust & 13.78 & 2.218 & 204 & 0 \\
\hline Authenticity & 12.19 & 2.057 & 204 & 0 \\
\hline Proaction & 14.43 & 2.529 & 204 & 0 \\
\hline Autonomy & 12.36 & 1.941 & 204 & 0 \\
\hline Collaboration & 13.72 & 2.189 & 204 & 0 \\
\hline Experimentation & 13.14 & 2.376 & 204 & 0 \\
\hline
\end{tabular}

Table 5 : OCTAPACE Correlation Matrix

\begin{tabular}{|c|c|c|c|c|c|c|c|c|c|}
\hline & & Openness & Confrontation & Trust & Authenticity & Proaction & Autonomy & Collaboration & Experimentation \\
\hline \multirow[t]{8}{*}{ Correlation } & Openness & 1.000 & .731 & .540 & .435 & .665 & .383 & .643 & .607 \\
\hline & Confrontation & .731 & 1.000 & .656 & .505 & .741 & .421 & .556 & .712 \\
\hline & Trust & .540 & .656 & 1.000 & .472 & .636 & .311 & .552 & .479 \\
\hline & Authenticity & .435 & .505 & .472 & 1.000 & .381 & .385 & .539 & .406 \\
\hline & Proaction & .665 & .741 & .636 & .381 & 1.000 & .308 & .507 & .635 \\
\hline & Autonomy & .383 & .421 & .311 & .385 & .308 & 1.000 & .491 & .458 \\
\hline & Collaboration & .643 & .556 & .552 & .539 & .507 & .491 & 1.000 & .512 \\
\hline & Experimentation & .607 & .712 & .479 & .406 & .635 & .458 & .512 & 1.000 \\
\hline \multirow[t]{8}{*}{ Sig. (1-tailed) } & Openness & & .000 & .000 & .000 & .000 & .000 & .000 & .000 \\
\hline & Confrontation & .000 & & .000 & .000 & .000 & .000 & .000 & .000 \\
\hline & Trust & .000 & .000 & & .000 & .000 & .000 & .000 & .000 \\
\hline & Authenticity & .000 & .000 & .000 & & .000 & .000 & .000 & .000 \\
\hline & Proaction & .000 & .000 & .000 & .000 & & .000 & .000 & .000 \\
\hline & Autonomy & .000 & .000 & .000 & .000 & .000 & & .000 & .000 \\
\hline & Collaboration & .000 & .000 & .000 & .000 & .000 & .000 & & .000 \\
\hline & Experimentation & .000 & .000 & .000 & .000 & .000 & .000 & .000 & \\
\hline
\end{tabular}

a. Determinant $=.010$

Table 6 : KMO and Bartlett's Test

\begin{tabular}{|c|c|c|}
\hline \multicolumn{2}{|c|}{$\begin{array}{l}\text { Kaiser-Meyer-Olkin Measure of Sampling } \\
\text { Adequacy. }\end{array}$} & .887 \\
\hline \multirow{3}{*}{$\begin{array}{l}\text { Bartlett's Test of } \\
\text { Sphericity }\end{array}$} & Approx. Chi-Square & 913.462 \\
\hline & Df & 28.000 \\
\hline & Sig. & .000 \\
\hline
\end{tabular}


Table 7 : Inverse of Correlation Matrix

\begin{tabular}{|l|c|c|c|c|c|c|c|c|}
\hline & Openness & Confrontation & Trust & Authenticity & Proaction & Autonomy & Collaboration & $\begin{array}{c}\text { Experim } \\
\text { entation }\end{array}$ \\
\hline Openness & 2.764 & -1.115 & .150 & .049 & -.571 & .047 & -.918 & -.163 \\
\hline Confrontation & -1.115 & 3.828 & -.764 & -.425 & -.906 & -.196 & .313 & -1.007 \\
\hline Trust & .150 & -.764 & 2.144 & -.267 & -.689 & .064 & -.495 & .197 \\
\hline Authenticity & .049 & -.425 & -.267 & 1.600 & .157 & -.170 & -.498 & -.015 \\
\hline Proaction & -.571 & -.906 & -.689 & .157 & 2.738 & .175 & -.028 & -.548 \\
\hline Autonomy & .047 & -.196 & .064 & -.170 & .175 & 1.468 & -.474 & -.392 \\
\hline Collaboration & -.918 & .313 & -.495 & -.498 & -.028 & -.474 & 2.289 & -.164 \\
\hline Experimentation & -.163 & -1.007 & .197 & -.015 & -.548 & -.392 & -.164 & 2.339 \\
\hline
\end{tabular}

Table 8 : Anti-image Matrices

\begin{tabular}{|c|c|c|c|c|c|c|c|c|c|}
\hline & & Openness & Confrontation & Trust & Authenticity & Proaction & Autonomy & Collaboration & Experimentation \\
\hline \multirow{8}{*}{$\begin{array}{l}\text { Anti-image } \\
\text { Covariance }\end{array}$} & Openness & .362 & -.105 & .025 & .011 & -.075 & .012 & -.145 & -.025 \\
\hline & Confrontation & -.105 & .261 & -.093 & -.069 & -.086 & -.035 & .036 & -.112 \\
\hline & Trust & .025 & -.093 & .467 & -.078 & -.117 & .020 & -.101 & .039 \\
\hline & Authenticity & .011 & -.069 & -.078 & .625 & .036 & -.072 & -.136 & -.004 \\
\hline & Proaction & -.075 & -.086 & -.117 & .036 & .365 & .044 & -.005 & -.086 \\
\hline & Autonomy & .012 & -.035 & .020 & -.072 & .044 & .681 & -.141 & -.114 \\
\hline & Collaboration & -.145 & .036 & -.101 & -.136 & -.005 & -.141 & .437 & -.031 \\
\hline & Experimentation & -.025 & -.112 & .039 & -.004 & -.086 & -.114 & -.031 & .427 \\
\hline \multirow{8}{*}{$\begin{array}{l}\text { Anti-image } \\
\text { Correlation }\end{array}$} & Openness & $.887 \mathrm{a}$ & -.343 & .062 & .024 & -.208 & .023 & -.365 & -.064 \\
\hline & Confrontation & -.343 & $.866^{a}$ & -.267 & -.172 & -.280 & -.083 & .106 & -.336 \\
\hline & Trust & .062 & -.267 & $.894^{\mathrm{a}}$ & -.144 & -.284 & .036 & -.223 & .088 \\
\hline & Authenticity & .024 & -.172 & -.144 & $.912^{\mathrm{a}}$ & .075 & -.111 & -.260 & -.008 \\
\hline & Proaction & -.208 & -.280 & -.284 & .075 & $.897 \mathrm{a}$ & .088 & -.011 & -.217 \\
\hline & Autonomy & .023 & -.083 & .036 & -.111 & .088 & $.888^{a}$ & -.259 & -.212 \\
\hline & Collaboration & -.365 & .106 & -.223 & -.260 & -.011 & -.259 & $.862^{a}$ & -.071 \\
\hline & Experimentation & -.064 & -.336 & .088 & -.008 & -.217 & -.212 & -.071 & $.906^{\mathrm{a}}$ \\
\hline
\end{tabular}

a. Measures of Sampling adequacy

Table 9 : Communalities

\begin{tabular}{|l|c|c|}
\hline & Initial & Extraction \\
\hline Openness & 1.000 & .689 \\
\hline Confrontation & 1.000 & .779 \\
\hline Trust & 1.000 & .585 \\
\hline Authenticity & 1.000 & .432 \\
\hline Proaction & 1.000 & .659 \\
\hline Autonomy & 1.000 & .342 \\
\hline Collaboration & 1.000 & .609 \\
\hline Experimentation & 1.000 & .627 \\
\hline
\end{tabular}

Extraction Method: Principal Component

Analysis. 
Table 10 : Total Variance Explained

\begin{tabular}{|c|c|c|c|c|c|c|}
\hline \multirow{2}{*}{ Component } & \multicolumn{5}{|c|}{ Initial Eigenvalues } & \multicolumn{3}{c|}{ Extraction Sums of Squared Loadings } \\
\hline & Total & \% of Variance & Cumulative \% & Total & \% of Variance & Cumulative \% \\
\hline 1 & 4.722 & 59.030 & 59.030 & 4.722 & 59.030 & 59.030 \\
\hline 2 & .869 & 10.857 & 69.886 & & & \\
\hline 3 & .682 & 8.519 & 78.405 & & & \\
\hline 4 & .483 & 6.036 & 84.442 & & & \\
\hline 5 & .464 & 5.796 & 90.238 & & & \\
\hline 6 & .324 & 4.045 & 94.283 & & & \\
\hline 7 & .269 & 3.359 & 97.642 & & & \\
\hline 8 & .189 & 2.358 & 100.000 & & & \\
\hline
\end{tabular}

Extraction Method: Principal Component Analysis.

Table 11 : Component Matrix

\begin{tabular}{|l|c|}
\hline \multirow{2}{*}{} & Component \\
\cline { 2 - 2 } & 1 \\
\hline Confrontation & .883 \\
\hline Openness & .830 \\
\hline Proaction & .812 \\
\hline Experimentation & .792 \\
\hline Collaboration & .780 \\
\hline Trust & .765 \\
\hline Authenticity & .657 \\
\hline Autonomy & .585 \\
\hline
\end{tabular}

Extraction Method: Principal Component Analysis.

a. 1 components extracted.

Table 12 : Reproduced Correlations

\begin{tabular}{|c|c|c|c|c|c|c|c|c|c|}
\hline & & Openness & Confrontation & Trust & Authenticity & Proaction & Autonomy & Collaboration & Experimentation \\
\hline \multirow{8}{*}{$\begin{array}{l}\text { Reproduced } \\
\text { Correlation }\end{array}$} & Openness & $.689 a$ & .733 & .635 & .545 & .674 & .485 & .648 & .658 \\
\hline & Confrontation & .733 & $.779^{a}$ & .675 & .580 & .717 & .516 & .689 & .699 \\
\hline & Trust & .635 & .675 & $.585^{\mathrm{a}}$ & .502 & .621 & .447 & .597 & .606 \\
\hline & Authenticity & .545 & .580 & .502 & $.432^{a}$ & .533 & .384 & .513 & .520 \\
\hline & Proaction & .674 & .717 & .621 & .533 & $.659 a$ & .475 & .634 & .643 \\
\hline & Autonomy & .485 & .516 & .447 & .384 & .475 & $.342^{a}$ & .456 & .463 \\
\hline & Collaboration & .648 & .689 & .597 & .513 & .634 & .456 & $.609^{a}$ & .618 \\
\hline & Experimentation & .658 & .699 & .606 & .520 & .643 & .463 & .618 & $.627 \mathrm{a}$ \\
\hline \multirow[t]{8}{*}{ Residualb } & Openness & & -.002 & -.095 & -.110 & -.009 & -.103 & -.005 & -.051 \\
\hline & Confrontation & -.002 & & -.019 & -.075 & .024 & -.095 & -.133 & .013 \\
\hline & Trust & -.095 & -.019 & & -.030 & .015 & -.136 & -.045 & -.127 \\
\hline & Authenticity & -.110 & -.075 & -.030 & & -.152 & .001 & .026 & -.114 \\
\hline & Proaction & -.009 & .024 & .015 & -.152 & & -.167 & -.126 & -.008 \\
\hline & Autonomy & -.103 & -.095 & -.136 & .001 & -.167 & & .034 & -.005 \\
\hline & Collaboration & -.005 & -.133 & -.045 & .026 & -.126 & .034 & & -.106 \\
\hline & Experimentation & -.051 & .013 & -.127 & -.114 & -.008 & -.005 & -.106 & \\
\hline
\end{tabular}

Extraction Method: Principal Component Analysis.

a. Reproduced communalities

b. Residuals are computed between observed and reproduced correlations. There are $14(50.0 \%)$ nonredundant residuals with absolute values greater than 0.05 . 
Table 13 : Component Score Coefficient Matrix

\begin{tabular}{|l|c|}
\hline & Component \\
\hline & 1 \\
\hline Openness & .176 \\
\hline Confrontation & .187 \\
\hline Trust & .162 \\
\hline Authenticity & .139 \\
\hline Proaction & .172 \\
\hline Autonomy & .124 \\
\hline Collaboration & .165 \\
\hline Experimentation & .168 \\
\hline
\end{tabular}

Extraction Method: Principal Component Analysis.

Rotation Method: Varimax with KaiserNormalization.

Component Scores.

Table 14 : Coefficients ${ }^{\mathrm{a}}$ of Public Vs. Private Sector Differentiation in Organizational Culture

\begin{tabular}{|c|c|c|c|c|c|c|}
\hline \multirow{2}{*}{\multicolumn{2}{|c|}{ Model }} & \multicolumn{2}{|c|}{ Unstandardized Coefficients } & \multirow{2}{*}{$\begin{array}{c}\begin{array}{c}\text { Standardized } \\
\text { Coefficients }\end{array} \\
\text { Beta }\end{array}$} & \multirow[b]{2}{*}{$\mathrm{T}$} & \multirow[b]{2}{*}{ Sig. } \\
\hline & & B & Std. Error & & & \\
\hline \multirow[t]{2}{*}{1} & (Constant) & -.091 & .096 & & -.948 & .344 \\
\hline & Sector & .193 & .140 & .097 & 1.381 & .169 \\
\hline
\end{tabular}

a. Dependent Variable: OverallCulture

Table 15 : Coefficients ${ }^{a}$ of Power Vs. IT Vs. Other Infrastructure Sector Knowledge Organizations in Organizational Culture

\begin{tabular}{|c|c|c|c|c|c|c|}
\hline & & \multicolumn{2}{|c|}{ Unstandardized Coefficients } & \multirow{2}{*}{$\begin{array}{c}\text { Standardized } \\
\text { Coefficients }\end{array}$} & \multirow[b]{2}{*}{$\mathrm{T}$} & \multirow[b]{2}{*}{ Sig. } \\
\hline \multicolumn{2}{|c|}{ Model } & B & Std. Error & & & \\
\hline \multirow[t]{3}{*}{1} & (Constant) & -.091 & .100 & & -.910 & .364 \\
\hline & dum var sec 1 & .196 & .155 & .094 & 1.263 & .208 \\
\hline & dum var sec 2 & .141 & .201 & .052 & .700 & .485 \\
\hline
\end{tabular}

a. Dependent Variable: OverallCulture

Table 16 : Coefficients ${ }^{\mathrm{a}}$ of Gender Differences

\begin{tabular}{|c|c|c|c|c|c|c|}
\hline \multirow{2}{*}{\multicolumn{2}{|c|}{ Model }} & \multicolumn{2}{|c|}{ Unstandardized Coefficients } & \multirow{2}{*}{$\begin{array}{c}\text { Standardized } \\
\text { Coefficients }\end{array}$} & \multirow[b]{2}{*}{$\mathrm{T}$} & \multirow[b]{2}{*}{ Sig } \\
\hline & & B & Std. Error & & & \\
\hline \multirow[t]{2}{*}{1} & (Constant) & -.056 & .076 & & -.737 & .462 \\
\hline & dum var gender & .347 & .189 & .128 & 1.833 & .068 \\
\hline
\end{tabular}

a. Dependent Variable: OverallCulture 